University of Wollongong

Research Online

Australian Institute for Innovative Materials -

Papers

Australian Institute for Innovative Materials

January 2018

\title{
Effect of Formation Potentials on Gassing of LiMn2O4//Li(4)Ti5O(12)/C Batteries
}

Lei Wen

Chinese Academy Of Sciences

Zeyi Wu

Shenzhen Kingrunning Energy Materials Co., Ltd

Peng Zhao

Northeastern University

Ji Liang

University of Wollongong, liangj@uow.edu.au

Hongze Luo

Council for Scientific \& Industrial Research

See next page for additional authors

Follow this and additional works at: https://ro.uow.edu.au/aiimpapers

Research Online is the open access institutional repository for the University of Wollongong. For further information contact the UOW Library: research-pubs@uow.edu.au 


\title{
Effect of Formation Potentials on Gassing of LiMn204//Li(4)Ti5O(12)/C Batteries
}

\author{
Abstract \\ Spinel Li4Ti5012 has been considered as a promising alternative material to graphite for lithium ion \\ batteries (LIBs) with improved safety and cycle life. Unfortunately, the destructive gas generation of \\ Li4Ti5012 and the associated cell swelling have been a major obstacle to the large-scale application of \\ LIBs using Li4Ti5012-based anodes. In this paper, we investigate the surface evolution of the anode in \\ LiMn204//Li4Ti5012/C cells and the role of formation potential on the gassing of LiMn204//Li4Ti5012/C \\ cells. It was found that an appropriate high potential formation protocol for LiMn204//Li4Ti5012/C \\ batteries can effectively inhibit the gassing and enhance the cycling performance of these LIBs. This is \\ mainly because under high formation protocol, an artificial flexible solid-electrolyte interphase film can be \\ formed on the surface of Li4Ti5012/C, which further prevents electrolyte decomposition at the \\ electrolyte//Li4Ti5012/C interface.

\section{Publication Details} \\ Wen, L., Wu, Z., Zhao, P., Liang, J., Luo, H., Liu, G. \& Li, F. (2018). Effect of Formation Potentials on Gassing \\ of LiMn2O4//Li(4)Ti5O(12)/C Batteries. Journal Of The Electrochemical Society, 166 (3), A5033-A5037. \\ Authors \\ Lei Wen, Zeyi Wu, Peng Zhao, Ji Liang, Hongze Luo, Guo-qiang Liu, and Feng Li
}


JeS Focus Issue of Selected Papers from IMLB 2018

\title{
Effect of Formation Potentials on Gassing of $\mathrm{LiMn}_{2} \mathrm{O}_{4} / / \mathrm{Li}_{4} \mathrm{Ti}_{5} \mathrm{O}_{12} / \mathrm{C}$ Batteries
}

\author{
Lei Wen, ${ }^{1}{ }^{1}$ Zeyi Wu, ${ }^{2}$ Peng Zhao, ${ }^{3}$ Ji Liang, ${ }^{4}$ Hongze Luo, ${ }^{5}$ Guo-qiang Liu, ${ }^{3}$ and Feng Li ${ }^{1, z}$ \\ ${ }^{I}$ Shenyang National Laboratory for Materials Science, Institute of Metal Research, Chinese Academy of Sciences, \\ Shenyang 110016, People's Republic of China \\ ${ }^{2}$ Shenzhen Kingrunning Energy Materials Co., Ltd., Guanlan, Shenzhen 518000, People's Republic of China \\ ${ }^{3}$ School of Metallurgy, Northeastern University, Shenyang 110016, People's Republic of China \\ ${ }^{4}$ Institute for Superconducting \& Electronic Materials, Australian Institute of Innovative Materials, University of \\ Wollongong, Innovation Campus, North Wollongong NSW 2500, Australia \\ ${ }^{5}$ Council for Scientific and Industrial Research, Pretoria 0001, South Africa
}

\begin{abstract}
Spinel $\mathrm{Li}_{4} \mathrm{Ti}_{5} \mathrm{O}_{12}$ has been considered as a promising alternative material to graphite for lithium ion batteries (LIBs) with improved safety and cycle life. Unfortunately, the destructive gas generation of $\mathrm{Li}_{4} \mathrm{Ti}_{5} \mathrm{O}_{12}$ and the associated cell swelling have been a major obstacle to the large-scale application of LIBs using $\mathrm{Li}_{4} \mathrm{Ti}_{5} \mathrm{O}_{12}$-based anodes. In this paper, we investigate the surface evolution of the anode in $\mathrm{LiMn}_{2} \mathrm{O}_{4} / / \mathrm{Li}_{4} \mathrm{Ti}_{5} \mathrm{O}_{12} / \mathrm{C}$ cells and the role of formation potential on the gassing of $\mathrm{LiMn}_{2} \mathrm{O}_{4} / / \mathrm{Li}_{4} \mathrm{Ti}_{5} \mathrm{O}_{12} / \mathrm{C}$ cells. It was found that an appropriate high potential formation protocol for $\mathrm{LiMn}_{2} \mathrm{O}_{4} / / \mathrm{Li}_{4} \mathrm{Ti}_{5} \mathrm{O}_{12} / \mathrm{C}$ batteries can effectively inhibit the gassing and enhance the cycling performance of these LIBs. This is mainly because under high formation protocol, an artificial flexible solid-electrolyte interphase film can be formed on the surface of $\mathrm{Li}_{4} \mathrm{Ti}_{5} \mathrm{O}_{12} / \mathrm{C}$, which further prevents electrolyte decomposition at the electrolyte//Li $\mathrm{Ti}_{5} \mathrm{O}_{12} / \mathrm{C}$ interface.

(C) The Author(s) 2018. Published by ECS. This is an open access article distributed under the terms of the Creative Commons Attribution 4.0 License (CC BY, http://creativecommons.org/licenses/by/4.0/), which permits unrestricted reuse of the work in any medium, provided the original work is properly cited. [DOI: 10.1149/2.0081903jes]

(cc) BY
\end{abstract}

Manuscript submitted September 11, 2018; revised manuscript received October 24, 2018. Published November 8, 2018. This paper is part of the JES Focus Issue of Selected Papers from IMLB 2018.

Spinel lithium titanate $\left(\mathrm{Li}_{4} \mathrm{Ti}_{5} \mathrm{O}_{12}\right.$, LTO $)$ has a high lithium intercalation voltage of $1.55 \mathrm{~V}\left(\mathrm{vs}\right.$. $\left.\mathrm{Li} / \mathrm{Li}^{+}\right)$with a theoretical capacity of $170 \mathrm{mAh} \mathrm{g}^{-1} .1,2$ LTO also has high thermal stability, superior safety, and long cycle life. ${ }^{3}$ Due to these merits, LTO has been intensively investigated as a very promising alternative anode material, especially for high energy batteries for hybrid electric vehicles (HEVs) or renewable energy storage plants. ${ }^{1,4-6}$

Although LTO shows these attractive characteristics, the severe gassing during the charge/discharge of LTO-based batteries has greatly hindered its broad application. This phenomenon has been observed in many systems, such as the $\mathrm{LiMn}_{2} \mathrm{O}_{4}(\mathrm{LMO}) / / \mathrm{LTO},{ }^{7,8}$ $\mathrm{LiNi}_{1 / 3} \mathrm{Co}_{1 / 3} \mathrm{Mn}_{1 / 3} \mathrm{O}_{2} / / \mathrm{LTO},{ }^{9}$ and $\mathrm{LiFePO}_{4} / / \mathrm{LTO}$ systems. ${ }^{10}$ The gassing mechanisms of LTO-based batteries have also received intensive attention from both industry and the research community. ${ }^{11}$ Some major factors that contribute to this issue have already been identified. (1) The trace water in LIBs: titanium oxide and its derivatives are also effective catalysts, which can effectively catalyse the decomposition of water into $\mathrm{H}_{2} \cdot{ }^{12}$ Therefore, the existence of trace water in the cathode, anode, and electrolyte may promote the gas generation in LTO-based LIBs, especially the generation of $\mathrm{H}_{2} .^{7,10,13}$ (2) $\mathrm{PF}_{5}$, the decomposed product of $\mathrm{LiPF}_{6}$, is a strong Lewis acid, which can initiate the chain-reaction of carbonate solvent decomposition and can be responsible for the gas generation. ${ }^{7}$ (3) The gassing in LTO batteries may also be caused by the high surface activity of LTO, which leads to interfacial side-reactions between LTO at the interface with the electrolyte. ${ }^{9}$ He et al. ${ }^{9}$ proved the formation of a solid-electrolyte interphase (SEI) film on the surface of LTO, even though the cutoff voltage during discharge was higher than $1.0 \mathrm{~V} \mathrm{vs.} \mathrm{Li}^{+} / \mathrm{Li}$. This layer is caused by the interfacial reactions between the anode and the electrolyte, rather than the reduction of the electrolyte at the SEI forming potential. ${ }^{14}$ This finding can reasonably clarify the gassing behavior of LTO, even in the single carbonate solvents. (4) The deposition of transition metal species, which come from the cathode, on the surface of LTO may further catalyse the electrolyte decomposition and further worsen the gassing issue of the LTO system, especially for the LMO//LTO battery. ${ }^{15}$
Despite the various gassing mechanisms that have been reported by far, there is no doubt that eliminating direct contact between LTO and the electrolyte is the most straightforward strategy to prevent the gassing. In order to inhibit these undesirable surface reactions of LTO, various coatings, such as carbon, ${ }^{16} \mathrm{AlF}_{3}{ }^{8}, \mathrm{YPO}_{4},{ }^{17}$ and $\mathrm{ZnO},{ }^{18}$ have been applied on LTO and been proven fairly effective in separating the LTO materials from the electrolyte, thus effectively suppressing electrolyte reduction/decomposition and gassing during charge/discharge. ${ }^{14}$

It is well known that the first few cycles of a LIB are regarded as the formation cycles. During these cycles, and particularly during the first charging, a complex reaction between the anode and electrolyte forms the SEI that covers the surface of the anode materials. ${ }^{19}$ The performance of LIBs heavily depends on the nature of the SEI layers, ${ }^{20-22}$ and it is generally believed that a dense, uniform, and flexible SEI film can suppress side-reactions and gassing for the graphite anode in a LIB.

Unfortunately, LTO has been regarded as an SEI-free material during cycling at the $\sim 1.5 \mathrm{~V}$ flat potential. ${ }^{11,23}$ Therefore, artificially constructing a stable and robust SEI film on the surface of LTO materials may be an important strategy to address the gassing issue of LTO materials. It is also well known that an appropriate formation protocol for LIBs is essential for the formation of a stable SEI on the graphite to prevent side-reactions. ${ }^{24-27}$

Addressing this, we have herein developed a rationally programmed formation protocol for the effective stabilization of a LTObased LIB cell. In this regard, we herein also investigated the anode surface evolution of LMO//LTO/C cells during the initial formation process. It has been found that, under a low formation potential, the carbon coating on LTO does not effectively function and gassing still occurs in this system. On the contrary, a high potential formation $(\sim 3.2 \mathrm{~V})$ protocol offers an effective strategy to construct an artificially-formed SEI film on the surface of LTO materials. This artificial SEI film can prevent the LTO particles from reacting with the surrounding electrolyte, thus significantly alleviating the gassing and enhancing its cycling performance.

\section{Experimental}

Assembly of $\mathrm{LMO} / \mathrm{LTO} / \mathrm{C}$ cells.-Stacked pouch cells were assembled using home-made LTO/C anode and commercial LMO (Type 

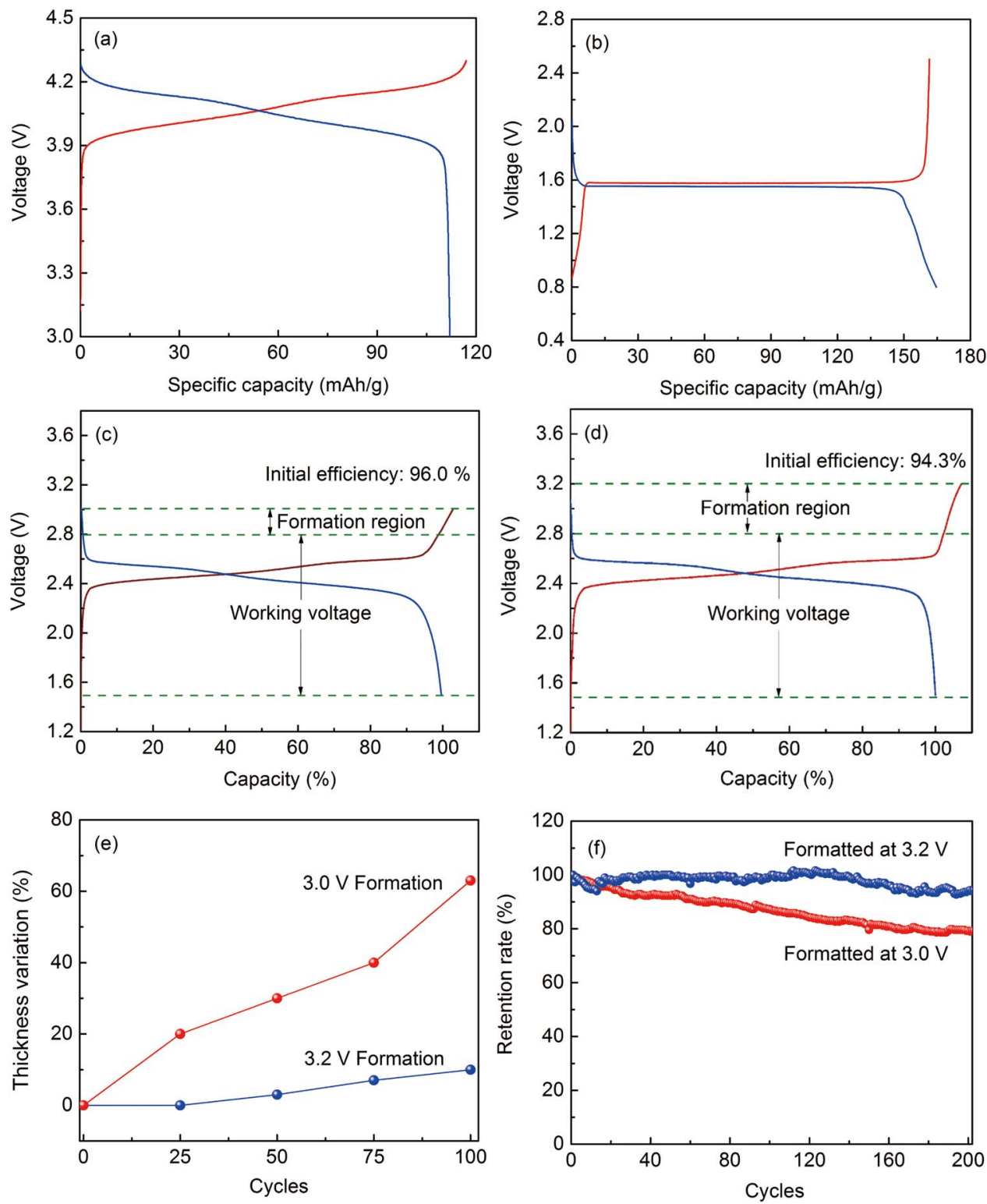

Figure 1. (a) First charge/discharge curves of LMO cathode, (b) first charge/discharge curves of LTO/C anode, (c) initial charge/discharge curves of LMO//LTO/C batteries with $3.0 \mathrm{~V}$ upper potential, (d) initial charge/discharge curves of LMO//LTO/C batteries with $3.2 \mathrm{~V}$ upper potential, (e) thickness variation of LMO//LTO/C pouch batteries with different upper potentials, and (f) cycling performance comparison of LMO//LTO/C batteries with different formation potentials.

LM011, Hunan Shanshan Advanced Materials Co. Ltd., Changsha, China) cathode materials. LTO/C anode was synthesized according to a previous report by a solid-state reaction method. ${ }^{15}$ For assembly in full batteries, the LMO electrode consisted of $94 \mathrm{wt} \% \mathrm{LMO}$, $3 \mathrm{wt} \%$ conductive carbon black, and $3 \mathrm{wt} \%$ polyvinylidene difluoride (PVDF) (HSV 900, Solvay, Belgium). The LTO/C electrode consisted of $92 \mathrm{wt} \%$ active materials, $3 \mathrm{wt} \%$ conductive carbon black, and $5 \mathrm{wt} \%$ PVDF as a binder. After being mixed thoroughly, the LMO and LTO/C slurries were coated onto aluminum and copper foil separately, with a subsequent calendering. The calendered densities of the LMO and $\mathrm{LTO} / \mathrm{C}$ electrode are $2.8 \mathrm{~g} / \mathrm{cm}^{3}$ and $1.7 \mathrm{~g} / \mathrm{cm}^{3}$, respectively. In this experiment, to design the coating density, LMO and LTO/C were first characterized in CR2025 coin cells, using Li metal as the negative electrode and $1 \mathrm{M} \mathrm{LiPF}_{6}$ in a 1:1:1 mixture of ethylene carbonate/ dimethyl carbonate/ diethyl carbonate (EC/DMC/DEC) was used as the electrolyte (Shenzhen Capchem Technology Co., Ltd., China). To improve the cycle performance and prevent LMO cathode from overcharging, the designed $\mathrm{LMO} / / \mathrm{LTO} / \mathrm{C}$ cell capacity is determined by LTO anode, and the capacity ratio of LMO//LTO/C is about $1.10 .^{28}$
To assemble LMO//LTO cells, $1 \mathrm{M} \mathrm{LiPF}_{6}$ in a 1:1:1 mixture of EC/DMC/DEC was used as the electrolyte (Shenzhen Capchem Technology Co., Ltd., China), and Celgard 2500 was used as the separator. The cathode, anode, and separator were stacked together to make the cell core, and then the core was put into aluminum plastic-laminated film pouches. The electrolyte was injected, and the batteries were sealed with a sealing machine. The cell assembly was conducted in an argon-filled MBraun glove box.

Characterization.-The formation and cycling tests of full cells were all performed using a LAND 2001A cell testing system (Wuhan Land, China) at room temperature. Two protocols were used to evaluate the effects of formation potentials, as shown in Fig. S1 in the supporting information. The high potential formation protocol (Fig. $\mathrm{S} 1 \mathrm{a}$ ) is as follows: (1) galvanostatic charge at $0.1 \mathrm{C}$ until the potential reaches $3.2 \mathrm{~V}$; (2) galvanostatic discharge at $0.1 \mathrm{C}$ until the potential reaches $1.5 \mathrm{~V}$; (3) after the first three formation cycles, galvanostatic charge at $1 \mathrm{C}$ until the potential reaches $3.0 \mathrm{~V}$; (4) potentiostatic charge at $3.0 \mathrm{~V}$ until the current is less than $0.1 \mathrm{C}$; and (5) galvanostatic 
discharge at $1 \mathrm{C}$ until potential reaches $1.5 \mathrm{~V}$. On the other hand, the low potential formation protocol is as follows: (1) galvanostatic charge at $0.1 \mathrm{C}$ until the potential reaches $3.0 \mathrm{~V}$ and (2) galvanostatic discharge at $0.1 \mathrm{C}$ until potential reaches $1.5 \mathrm{~V}$. After the first three formation cycles, steps (3), (4), and (5) are identical to those in the low potential formation protocol (Fig. S1b). Fig. S2 shows the procedure for measuring the thickness of the LIBs after cycling.

To investigate the surface composition of the electrodes, full cells were disassembled in a high-purity Ar atmosphere at different formation potentials with respect to the discharged state, rinsed thoroughly with dimethyl carbonate (DMC) solution and transferred to the Fourier transform infrared spectroscopy (FTIR, Nicolet iS 5) and X-Ray photoelectron spectroscopy (XPS) apparatus. XPS was conducted on an ESCALAB 250 spectrometer using an $\mathrm{Al} \mathrm{K} \alpha$ radiation.

\section{Results}

Figs. 1a and $1 \mathrm{~b}$ show the first charge/discharge profile of the LMO cathode and LTO/C anode, which have specific capacities of 110 and $165 \mathrm{mAh} / \mathrm{g}$, respectively. The effect of the upper formation potential on the electrochemical performance and gassing of the LMO//LTO/C system was then evaluated from pouch cells containing these electrode materials. Figs. 1c and 1d shows the first formation curves of the cells with different upper potentials at $0.1 \mathrm{C}$. Obviously, the cell obtained at the high upper formation potential $(3.2 \mathrm{~V})$ showed a significantly lower initial coulombic efficiency $(94.3 \%$, Fig. 1d) than that obtained at the normal formation potential $(3.0 \mathrm{~V}, 96.0 \%$, Fig. 1c). With the increasing cycles, the cells obtained at the ordinary formation potential, however, showed an apparent gassing and swelling. Fig. 1e shows the changes in the thickness of the two types of LMO//LTO/C cells during cycling. It can be seen that the ordinarily formatted cells show about a $60 \%$ increase in thickness after 100 cycles, while the ones formatted at the high potential only show about a $10 \%$ thickness increase or swelling. Moreover, the high-potential formatted cells also showed better cycling performance than those formatted at the ordinary potential (Fig. 1f). The capacity retention of the batteries formatted at $3.2 \mathrm{~V}$ is about $94.2 \%$ after 200 cycles. In contrast, the capacity retention of those formatted at $3.0 \mathrm{~V}$ batteries is only $\sim 79 \%$ after 200 cycles. This clearly indicates that the high-potential formation protocol not only effectively suppresses gassing, but also significantly improves the electrochemical performance.

The surface compositions of the LTO/C electrodes after formatting at different formation potentials were then characterized by FTIR spectroscopy. Fig. 2 shows the FTIR curves of PVDF binder and the LTO/C electrodes formatted at 2.8, 3.0 and 3.2 V in the LMO//LTO/C cells. It can be found that the bands for $\left(\mathrm{CH}_{2} \mathrm{OCO}_{2} \mathrm{Li}\right)_{2}$ and $\mathrm{Li}_{2} \mathrm{CO}_{3}$ in the high-potential formatted electrodes were stronger than those in the low-potential formatted ones. Since these newly formed species are characteristic constituents of the anode SEI film in a LIB,${ }^{21}$ it can be reasonably deduced that this high formation potential would possibly lead to a desirable dense SEI on the surface of the LTO/C electrode.

In order to identify the chemical species on the surface of the formatted LTO/C, XPS was then conducted on the electrodes formatted at the different formation potentials of $2.8,3.0$, and $3.2 \mathrm{~V}$ at room temperature (Fig. 3). In the high-resolution C 1s spectra, the LTO/C electrode formatted at $3.2 \mathrm{~V}$ shows the highest content of polyethylene oxide (PEO, $286.5 \mathrm{eV}$ ) in comparison with the electrodes formatted at the lower potentials. In addition, in the $\mathrm{O} 1 \mathrm{~s}$ spectra of the materials, a peak at $\sim 533 \mathrm{eV}$ could be observed in all the spectra. This peak corresponding to PEO is the highest in the high-potential formatted sample, agreeing with the results from the $\mathrm{C} 1 \mathrm{~s}$ spectra and thus further confirming the successful formation of the PEO polymer surface layer during the high potential formation. ${ }^{24}$ Moreover, as shown in the $\mathrm{F} 1 \mathrm{~s}$ spectra, peaks that can be assigned to both PVDF $(688 \mathrm{eV})$ and $\mathrm{LiF}$ $(686 \mathrm{eV})$ can be found in the three samples. ${ }^{29}$ As the formation potential goes higher, the LiF content also becomes larger, which confirms the successful formation of the SEI at high formation potentials.

In summary, the FTIR, XPS, and electrochemical performance results all prove that a different electrochemical interface reaction might

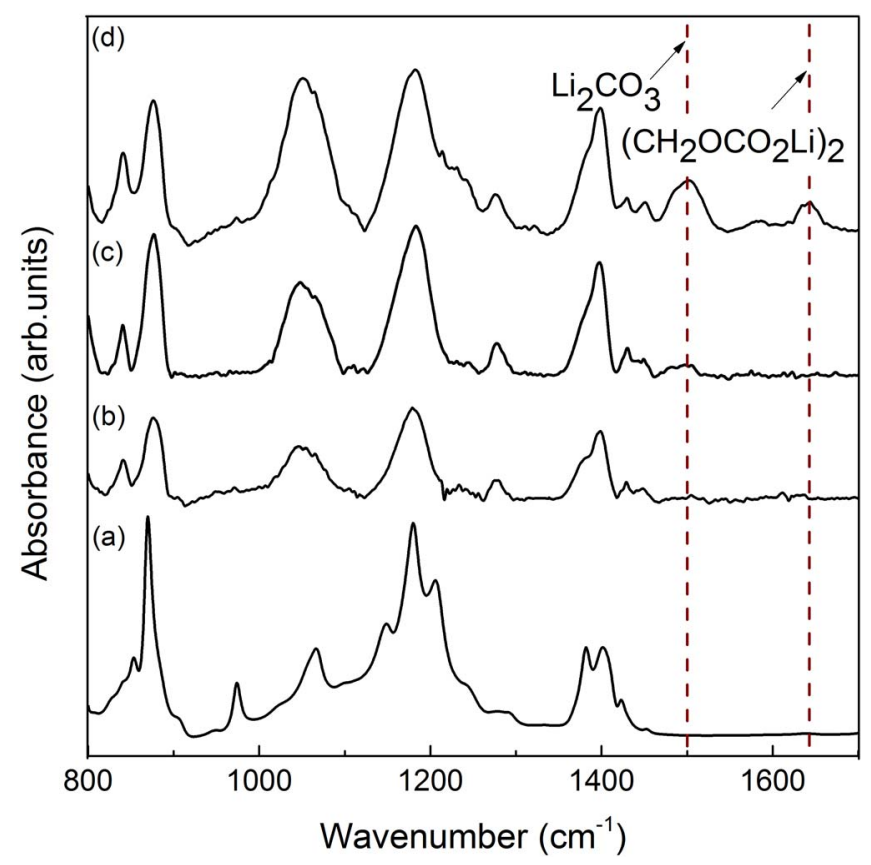

Figure 2. FTIR curves of (a) PVDF, and (b)-(d) LTO/C electrode formatted at $2.8,3.0$, and $3.2 \mathrm{~V}$, respectively.

occur at the high formation potential of $3.2 \mathrm{~V}$, which can be linked to less gassing and the superior cycling performance of $\mathrm{LMO} / / \mathrm{LTO} / \mathrm{C}$ batteries, as shown in Fig. 1.

\section{Discussion}

During the initial formation process for graphite-based LIBs, gas generation is one of the major issues, as a result of electrolyte decomposition and SEI formation. Typically, the generated gasses are evacuated after formation during the battery fabrication. More importantly, after the initial formation, the SEI film still acts as a barrier that prevents continuous electrolyte decomposition during the subsequent charge/discharge processes, which completely suppresses the gassing of graphite LIBs. One significant difference between LTO and graphite is the high lithium intercalation potential of LTO $\left(1.5 \mathrm{~V}\right.$ vs. $\left.\mathrm{Li}^{+} / \mathrm{Li}\right)$, which is far higher than that of the SEI formation potential (0.6-0.8 V vs. $\left.\mathrm{Li}^{+} / \mathrm{Li}\right)$. Therefore, an appropriate formation protocol is essential for providing a stable SEI on the LTO/C anode (at low potentials vs. $\mathrm{Li}^{+} / \mathrm{Li}$ ) in order to prevent the irreversible and excessive consumption of electrolyte and lithium ions.

As shown in Fig. 4, in the initial charge stage of the full cell, the potential of LTO is maintained at about $1.5 \mathrm{~V}$, and the inorganic components (mainly including $\mathrm{Li}_{2} \mathrm{CO}_{3}$ and $\mathrm{LiF}$ ) of the SEI layer might be produced, as demonstrated in Fig. 3A. At the end of the charge stage of the full cell (i.e., the high potential formation region in Fig. 4), the potential of LTO can drop down to the SEI formation potential $(\sim 0.6 \mathrm{~V})$. At this stage, the carbon-containing species in the SEI are mainly a mixture of $\mathrm{Li}_{2} \mathrm{CO}_{3}$ and PEO oligomers $\left(-\mathrm{CH}_{2}-\mathrm{CH}_{2}-\right.$ $\mathrm{O}-)_{\mathrm{n}}$, as shown in Figs. $3 \mathrm{~B}$ and $3 \mathrm{C}$. Their formation could be due to the decomposition of solvents, leading to the formation of a uniform coating layer (Fig. 4). ${ }^{29,30}$

More importantly, it is generally accepted that an ideal SEI film should have the following properties: (1) high electrical resistance, high cation selectivity, and permeability; (2) a proper thickness with an intact structure; and (3) flexible properties, and tolerance to expansion and contraction stresses (since the SEI layer must accommodate the expanding and contracting sub-surfaces during cycling). ${ }^{15,21,31}$ Edström et al. ${ }^{32}$ described and demonstrated that the SEI has a heterogenic structure, which is composed of inorganic $\mathrm{LiF}$ and $\mathrm{Li}_{2} \mathrm{CO}_{3}$ close to the electrode surface and an organic polymeric component 
A
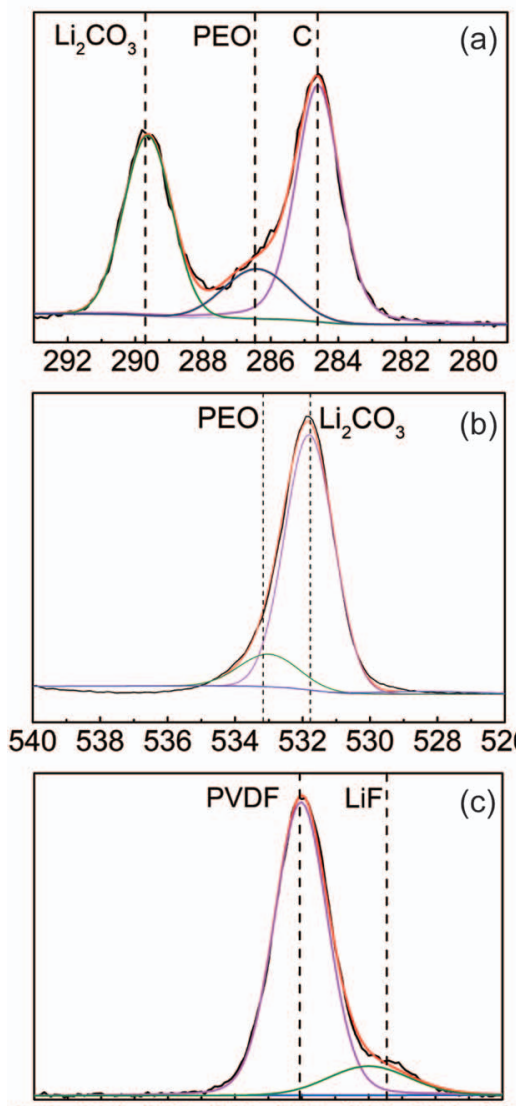

(c)
B
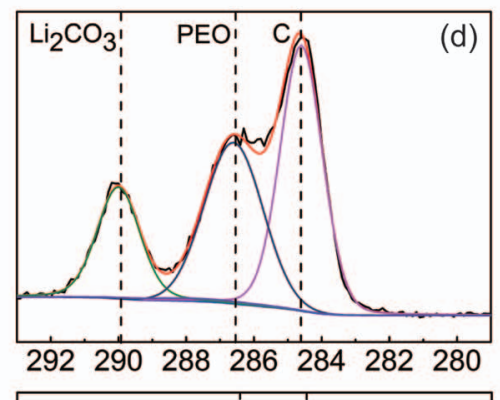

C

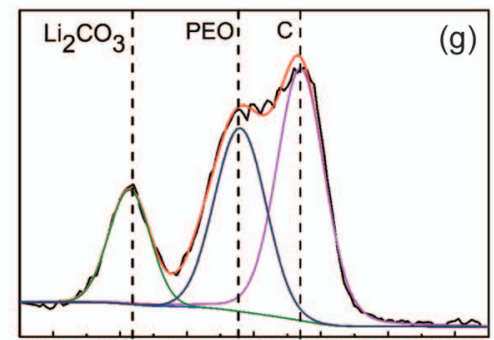

$292 \quad 290288286284282280$

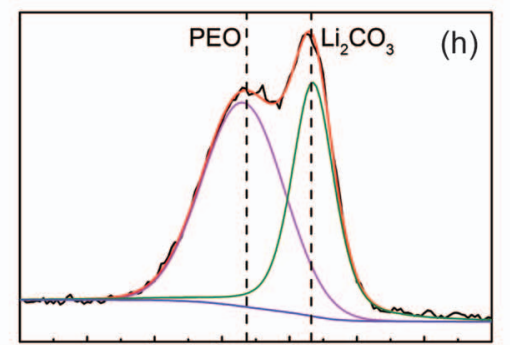

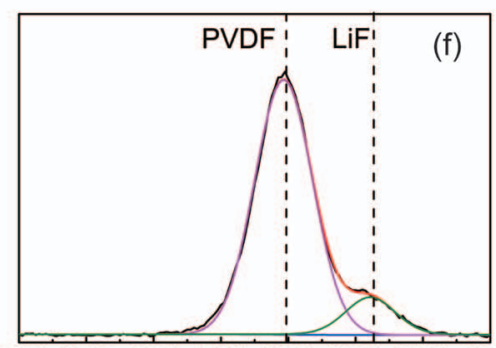

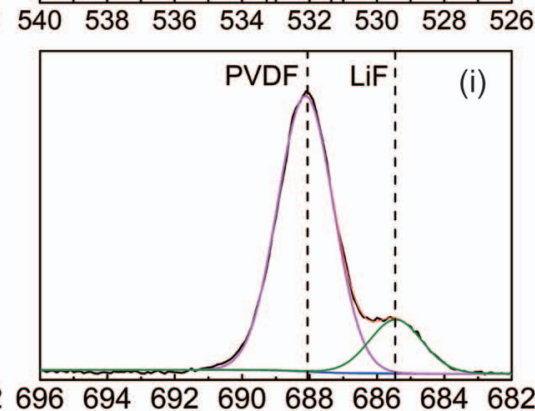

Figure 3. XPS spectra of LTO/C electrodes after different formation protocols: (A) $2.8 \mathrm{~V}$ formation, (B) $3.0 \mathrm{~V}$ formation and (C) $3.2 \mathrm{~V}$ formation. (a), (d), and (g) are $\mathrm{C} 1 \mathrm{~s}$ spectra, (b), (e), and (h) are $\mathrm{O} 1 \mathrm{~s}$ spectra, and (c), (f), and (i) are $\mathrm{F} 1 \mathrm{~s}$ spectra.

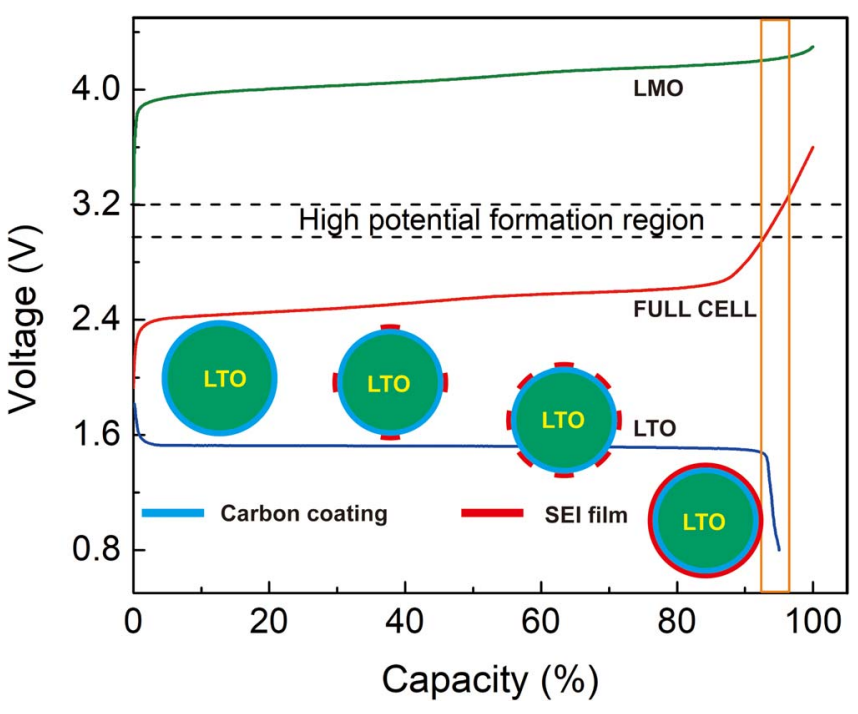

Figure 4. Potential variation of cathode, anode, and LMO//LTO/C full batteries, and surface evolution of LTO/C electrode during formation.

close to the electrolyte. Soto et al. ${ }^{33}$ also suggested that an increasing amount of polymeric compounds would lead to compact SEI layers and a relatively stable outer organic-SEI layer. More importantly, the higher polymer content in the SEI layer and its softness can provide flexibility to the SEI and fill the voids. ${ }^{34}$ This intact and flexible layer may better prevent the electrolyte from coming into contact with the catalytically active sites of the electrode materials. ${ }^{35}$ For example, Brett et al. ${ }^{36}$ found that an SEI composed of $\mathrm{Li}_{2} \mathrm{CO}_{3}$ and polymers appeared to be particularly stable on the composite anode materials, and this improved SEI layer significantly enhanced the cycling performance of the battery. A good SEI layer on the graphite anode can also be beneficial to the battery's high-temperature performance. ${ }^{37}$ Therefore, a high-potential formation protocol would finally lead to a uniform protective SEI layer on the surface of the anode, and this layer with its high content of flexible PEO can be regarded as a flexible barrier to prevent the side-reactions and gassing in LMO//LTO/C batteries.

\section{Conclusions}

For the purpose of suppressing the gas generation of LMO//LTO/C LIB systems, we have developed a high-potential formation protocol, which can result in a stable SEI film on the surfaces of LTO/C materials. It was found that, with the formation potential increased to above $3.0-3.2 \mathrm{~V}$, a larger proportion of flexible PEO component was formed in the interface layer, which contributed to less gassing and improved cycling performance. Therefore, the high-potential formation protocol is very effective for suppressing the gas generation in the LTO battery, and this easy high-potential formation protocol makes LTO/C anode a very promising anode material for large-scale LIBs.

\section{Acknowledgments}

This work was supported by the Ministry of Science and Technology of China (2016YBF0100100, 2014CB932402), the National 
Natural Science Foundation of China (NSFC, nos. 51521091 and 51525206), the "Strategic Priority Research Program" of the Chinese Academy of Sciences (CAS) (XDA09010104), the Key Research Program of the Chinese Academy of Sciences (grant No. KGZDEW-T06), the CAS/State Administration of Foreign Experts Affairs (SAFEA) International Partnership Program for Creative Research Teams, and the Australian Research Council (ARC) through Discovery Early Career Researcher Awards (DECRA, DE170100871). The authors thank Dr. Tania Silver for critical reading and revision of the manuscript.

\section{ORCID}

Lei Wen (1D https://orcid.org/0000-0001-5988-8778

Feng Li (D) https://orcid.org/0000-0002-2213-9914

\section{References}

1. E. Ferg, R. J. Gummow, A. Dekock, and M. M. Thackeray, J. Electrochem. Soc., 141 L147 (1994).

2. Y. R. Wen, X. Chen, X. Lu, and L. Gu, J. Energy Chem., 27, 1397 (2018).

3. D. Capsoni, M. Bini, V. Massarotti, P. Mustarelli, G. Chiodelli, C. B. Azzoni, M. C. Mozzati, L. Linati, and S. Ferrari, Chem. Mat., 20, 4291 (2008).

4. B. H. Li, C. P. Han, Y. B. He, C. Yang, H. D. Du, Q. H. Yang, and F. Y. Kang, Energy Environ. Sci., 5, 9595 (2012).

5. X. Lu, L. Zhao, X. Q. He, R. J. Xiao, L. Gu, Y. S. Hu, H. Li, Z. X. Wang, X. F. Duan L. Q. Chen, J. Maier, and Y. Ikuhara, Adv. Mater, 24, 3233 (2012).

6. C. F. Liu, S. H. Wang, C. K. Zhang, H. Y. Fu, X. H. Nan, Y. Yang, and G. Z. Cao, Energy Storage Mater., 5, 93 (2016).

7. I. Belharouak, G. M. Koenig, T. Tan, H. Yumoto, N. Ota, and K. Amine, J. Electrochem. Soc., 159, A1165 (2012).

8. W. Li, X. Li, M. Z. Chen, Z. W. Xie, J. X. Zhang, S. Q. Dong, and M. Z. Qu, Electrochim. Acta, 139, 104 (2014).

9. Y. B. He, B. H. Li, M. Liu, C. Zhang, W. Lv, C. Yang, J. Li, H. D. Du, B. Zhang, Q. H. Yang, J. K. Kim, and F. Y. Kang, Sci. Rep., 2 (2012).

10. R. Bernhard, S. Meini, and H. A. Gasteiger, J. Electrochem. Soc., 161, A497 (2014).

11. Y. Shi, L. Wen, M. J. Wu, and F. Li, Prog. Chem., 29, 149 (2017).

12. G. Liu, H. G. Yang, J. Pan, Y. Q. Yang, G. Q. Lu, and H. M. Cheng, Chem. Rev., 114 9559 (2014).
13. R. Bernhard, M. Metzger, and H. A. Gasteiger, J. Electrochem. Soc., 162, A1984 (2015).

14. C. P. Han, Y. B. He, M. Liu, B. H. Li, Q. H. Yang, C. P. Wong, and F. Y. Kang, J. Mater. Chem. A, 5, 6368 (2017).

15. L. Wen, Z. Y. Wu, H. Z. Luo, R. S. Song, and F. Li, J. Electrochem. Soc., 162, A3038 (2015).

16. Y. B. He, F. Ning, B. H. Li, Q. S. Song, W. Lv, H. D. Du, D. Y. Zhai, F. Y. Su, Q. H. Yang, and F. Y. Kang, J. Power Sources, 202, 253 (2012).

17. X. Li, J. Xu, J. Zhu, K. J. Zhang, M. S. Wang, and Y. Huang, Mater. Lett., 200, 71 (2017)

18. C. P. Han, Y. B. He, H. F. Li, B. H. Li, H. D. Du, X. Y. Qin, and F. Y. Kang, Electrochim. Acta, 157, 266 (2015).

19. B. K. Antonopoulos, C. Stock, F. Maglia, and H. E. Hoster, Electrochim. Acta, 269, 331 (2018).

20. E. Peled, D. Golodnitsky, and G. Ardel, J. Electrochem. Soc., 144, L208 (1997).

21. E. Peled and S. Menkin, J. Electrochem. Soc., 164, A1703 (2017).

22. E. Markevich, G. Salitra, and D. Aurbach, ACS Energy Lett., 2, 1337 (2017).

23. K. Wu, J. Yang, Y. Zhang, C. Y. Wang, and D. Y. Wang, J. Appl. Electrochem., 42 989 (2012).

24. S. J. An, J. L. Li, C. Daniel, D. Mohanty, S. Nagpure, and D. L. Wood, Carbon, 105, 52 (2016).

25. V. A. Agubra, J. W. Fergus, R. J. Fu, and S. Y. Choe, J. Power Sources, 270, 213 (2014).

26. Y. B. He, B. H. Li, Q. H. Yang, H. D. Du, F. Y. Kang, G. W. Ling, and Z. Y. Tang, J. Solid State Electrochem., 15, 1977 (2011)

27. D. J. Yang, H. L. Zhao, J. P. Wang, Y. Sun, N. N. Wu, and W. H. Tian, J. Solid State Electrochem., 18, 1907 (2014).

28. H. F. Xiang, X. Zhang, Q. Y. Jin, C. P. Zhang, C. H. Chen, and X. W. Ge, J. Power Sources, 183, 355 (2008).

29. R. Dedryvere, H. Martinez, S. Leroy, D. Lemordant, F. Bonhomme, P. Biensan, and D. Gonbeau, J. Power Sources, 174, 462 (2007).

30. H. Yoshida, T. Fukunaga, T. Hazama, M. Terasaki, M. Mizutani, and M. Yamachi, J. Power Sources, 68, 311 (1997).

31. X. B. Cheng, R. Zhang, C. Z. Zhao, F. Wei, J. G. Zhang, and Q. Zhang, Adv. Sci., 3, $1500213(2016)$

32. K. Edström, M. Herstedt, and D. P. Abraham, J. Power Sources, 153, 380 (2006).

33. F. A. Soto, Y. G. Ma, J. M. M. de la Hoz, J. M. Seminario, and P. B. Balbuena, Chem Mat., 27, 7990 (2015).

34. J. Yan, J. Zhang, Y. C. Su, X. G. Zhang, and B. J. Xia, Electrochim. Acta, 55, 1785 (2010).

35. A. Schiele, B. Breitung, T. Hatsukade, B. B. Berkes, P. Hartmann, J. Janek, and T. Brezesinski, ACS Energy Lett., 2, 2228 (2017).

36. C. N. Cao and B. L. Lucht, J. Electrochem. Soc., 165, A2154 (2018).

37. H. Ota, Y. Sakata, A. Inoue, and S. Yamaguchi, J. Electrochem. Soc., 151, A1659 (2004). 